\section{Gastric emphysema after endoscopic submucosal dissection}

A 62-year-old male patient with underlying Type 2 diabetes mellitus and hypertension underwent screening esophagogastroduodenoscopy. A 5-cm flat nodular mucosal lesion, which was confirmed to be high grade dysplasia, was noted at the upper body along the lesser curvature, just below the cardia ( $\bullet$ Fig. 1 ).

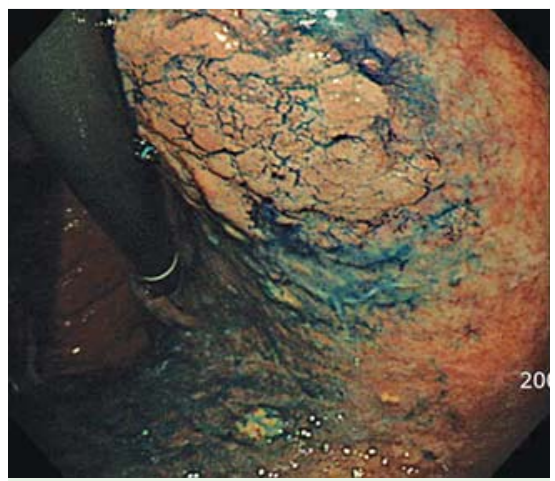

Fig. 1 A flat nodular mucosal lesion at the upper body along the lesser curvature was diagnosed as high grade dysplasia.
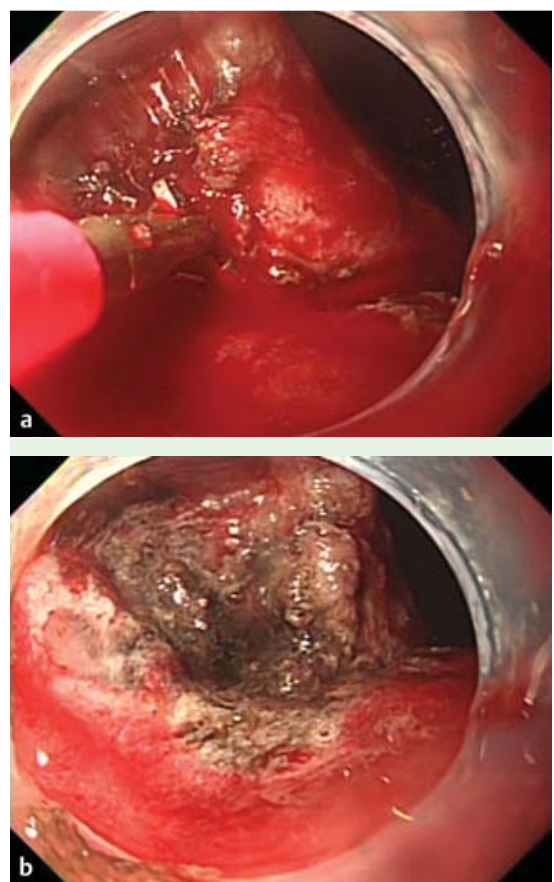

Fig. 2 Extensive bleeding during endoscopic submucosal dissection required frequent electrohemostasis. a Electrohemostasis using hemostatic forceps with $80 \mathrm{~W}$ soft-mode coagulation. $\mathbf{b}$ Extensive tissue burn injury due to excessive current application.
Endoscopic submucosal dissection (ESD) was performed at a universal setting with high frequency apparatus (VIO300D; ERBE, Tübingen, Germany). During the procedure, large amounts of bleeding occurred, which necessitated frequent electrohemostasis, resulting in extensive tissue burn injury ( $\bullet$ Fig. 2 a, b).

The total procedure time was 4 hours and 30 minutes. The following day, fever of $38.5^{\circ} \mathrm{C}$ and abdominal pain developed. Perforation was suspected, and abdominal computed tomography scan was performed. Intramural gas was present from the plane of the fundal portion of the stomach to the posterior wall of the midbody, with accompanying edematous wall thickening ( $\bullet$ Fig. $3 a$ ).

Intramural gas was even more evident in the lung window view ( $\mathbf{F i g . 3 b}$ ). The triad of fever, abdominal pain, and air within the gastric wall led us to consider the possibility of a potentially fatal emphysematous gastritis; thus, broad spectrum antibiotics were promptly applied (ceftriaxone $2 \mathrm{~g}$ i.v. q.d., metronidazole $500 \mathrm{mg}$ i.v. t.i.d.) [1 - 2].

Fortunately, the fever and abdominal pain quickly subsided, just a day after its initial manifestation. Due to the benign course of the patient's condition, we were able to make a diagnosis of gastric emphysema (gastric pneumatosis) [3].

Well known complications of ESD are pain, bleeding, perforation, and stricture [4-5]. To our knowledge, this represents the first reported case of gastric emphysema as a complication of ESD. We suggest the possible etiology to be the persistent intragastric pressure elevation due to a prolonged procedure and excessive current application for hemostasis. Due to its fast absorption, insufflation with carbon dioxide may be considered in cases of prolonged ESD in order to prevent emphysema.

\section{Endoscopy_UCTN_Code_CPL_1AH_2AZ}

\section{Competing interests: None}
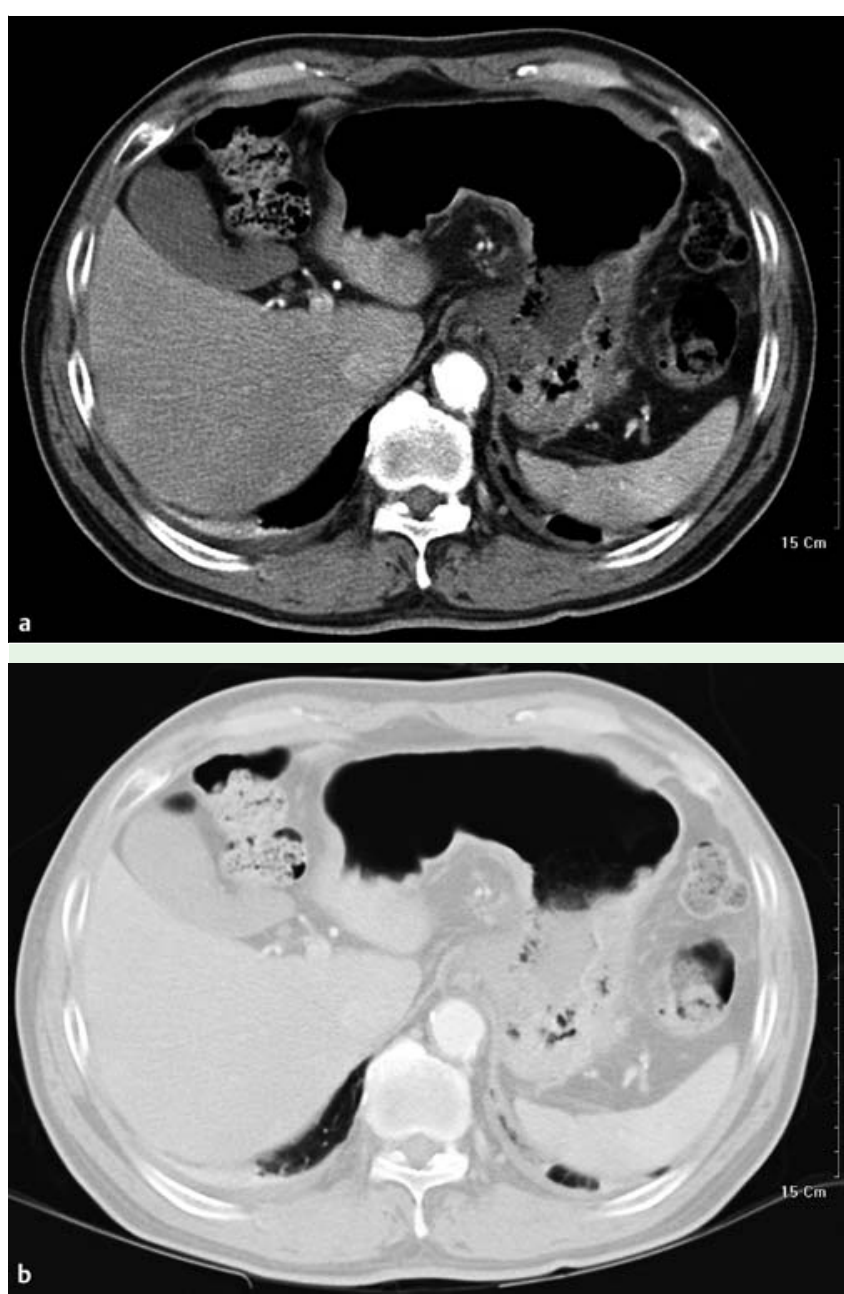

Fig. 3 Conventional computed tomography scan images. a Gas in the stomach wall from the plane of the fundal portion to the posterior wall of the mid-body, with edematous wall thickening. b Lung window setting demonstrated even more intramural gas. 
Y. S. Hyun, D. S. Han, H. L. Lee, J. H. Bae,

\section{S. Eun}

Department of Gastroenterology, Hanyang

University College of Medicine, Guri, Korea

\section{References}

1 Allan K, Barriga J, Afshani $M$ et al. Emphysematous gastritis. Am J Med Sci 2005; 329: $205-207$

2 Yalamanchili M, Cady W. Emphysematous gastritis in a hemodialysis patient. South Med J 2003; 96: 84-88

3 Zenooz NA, Robbin MR, Perez V. Gastric pneumatosis following nasogastric tube placement: a case report with literature review. Emerg Radiol 2007; 13: 205 - 207

4 Chung IK, Lee JH, Lee SH et al. Therapeutic outcomes in 1000 cases of endoscopic submucosal dissection for early gastric neoplasms: Korean ESD Study Group multicenter study. Gastrointest Endosc 2009; 69: $1228-1235$

5 Tsunada S, Ogata S, Mannen K et al. Case series of endoscopic balloon dilation to treat a stricture caused by circumferential resection of the gastric antrum by endoscopic submucosal dissection. Gastrointest Endosc 2008; 67: 979-983
Bibliography

DOI $10.1055 / \mathrm{s}-0030-1255805$

Endoscopy 2011; 43: E83-E84

(c) Georg Thieme Verlag KG Stuttgart · New York . ISSN 0013-726X

\section{Corresponding author}

D. S. Han, MD, PhD

Department of Internal Medicine

Hanyang University Guri Hospital 249-1

Gyomun-Dong

Guri City

Gyunggi-Do 471-710

Korea

Fax: +82-31-5552998

hands@hanyang.ac.kr 